\title{
Search for genes responsible for the remarkably high acetic acid tolerance of a Zygosaccharomyces bailii-derived interspecies hybrid strain
}

Margarida Palma ${ }^{\dagger}$, Filipa de Canaveira Roque ${ }^{\dagger}$, Joana Fernandes Guerreiro, Nuno Pereira Mira, Lise Queiroz and Isabel Sá-Correia ${ }^{*}$

\begin{abstract}
Background: Zygosaccharomyces bailii is considered the most problematic acidic food spoilage yeast species due to its exceptional capacity to tolerate high concentrations of weak acids used as fungistatic preservatives at low $\mathrm{pH}$. However, the mechanisms underlying its intrinsic remarkable tolerance to weak acids remain poorly understood. The identification of genes and mechanisms involved in Z. bailii acetic acid tolerance was on the focus of this study. For this, a genomic library from the highly acetic acid tolerant hybrid strain ISA1307, derived from Z. bailii and a closely related species and isolated from a sparkling wine production plant, was screened for acetic acid tolerance genes. This screen was based on the transformation of an acetic acid susceptible Saccharomyces cerevisiae mutant deleted for the gene encoding the acetic acid resistance determinant transcription factor Haa1.

Results: The expression of 31 different DNA inserts from ISA1307 strain genome was found to significantly increase the host cell tolerance to acetic acid. The in silico analysis of these inserts was facilitated by the recently available genome sequence of this strain. In total, 65 complete or truncated ORFs were identified as putative determinants of acetic acid tolerance and an S. cerevisiae gene homologous to most of them was found. These include genes involved in cellular transport and transport routes, protein fate, protein synthesis, amino acid metabolism and transcription. The role of strong candidates in Z. bailii and S. cerevisiae acetic acid tolerance was confirmed based on homologous and heterologous expression analyses.

(Continued on next page)
\end{abstract}

\footnotetext{
* Correspondence: isacorreia@tecnico.ulisboa.pt

Margarida Palma and Filipa de Canaveira Roque are co-first authors.

†Equal contributors

Department of Bioengineering, Institute for Bioengineering and Biosciences, Instituto Superior Técnico, Universidade de Lisboa, Av. Rovisco Pais, 1049-001 Lisbon, Portugal
} 
(Continued from previous page)

Conclusions: ISA1307 genes homologous to S. cerevisiae genes GYP8, WSC4, PMT1, KTR7, RKR1, TIF3, ILV3 and MSN4 are proposed as strong candidate determinants of acetic acid tolerance. The ORF ZBAI_02295 that contains a functional domain associated to the uncharacterised integral membrane proteins of unknown function of the DUP family is also suggested as a relevant tolerance determinant. The genes ZbMSN4 and ZbTIF3, encoding a putative stress response transcription factor and a putative translation initiation factor, were confirmed as determinants of acetic acid tolerance in both Z. bailii and S. cerevisiae. This study provides valuable indications on the cellular components, pathways and processes to be targeted in order to control food spoilage by the highly acetic acid tolerant Z. bailii and Z. bailii-derived strains. Additionally, this information is essential to guide the improvement of yeast cells robustness against acetic acid if the objective is their use as cell factories.

Keywords: Yeast, Zygosaccharomyces bailii, Acetic acid tolerance genes, Yeast hybrid strains, Food spoilage yeasts, Weak acid food preservatives

\section{Background}

Zygosaccharomyces bailii is considered the most problematic spoilage yeast found in the food and beverage industry, particularly in acidic foods, soft drinks, fruit juices, dairy products and salad dressings [1, 2]. This yeast species ability to cause spoilage derives from its outstanding intrinsic capacity to resist to weak acids widely used as fungistatic preservatives, such as acetic, propionic, benzoic and sorbic acids [1-4]. Understanding the mechanisms of weak acid resistance is central to the development and implementation of more effective food and beverage preservation strategies in order to minimise economic losses. Although Z. bailii is the spoilage yeast that exhibits the highest level of tolerance to acetic acid, most of the scientific contributions on the mechanisms underlying adaptation and resistance to acetic acid in yeast have been focused on the more susceptible experimental model Saccharomyces cerevisiae [5-9]. At a $\mathrm{pH}$ equal or below its $\mathrm{p} K \mathrm{a}$ (4.75), acetic acid is mainly in the undissociated form that can diffuse across the plasma membrane. Once in the near neutral cytosol, acetic acid dissociates leading to the accumulation of protons and acetate. The acidification of the cytosol leads to the inhibition of metabolic activity and to the dissipation of the proton gradient across plasma membrane required for secondary transport $[10,11]$. To counteract this effect, the plasma membrane protonpumping ATPase (PM $\mathrm{H}^{+}$-ATPase) is activated in acetic acid-stressed S. cerevisiae cells [12]. The involvement of $Z$. bailii $\mathrm{PM} \mathrm{H}^{+}$-ATPase in the active export of protons from cells challenged by weak acid preservatives, namely benzoic acid, was also demonstrated, suggesting that both yeasts share this response mechanism [13]. Given that the charged acetate counterion is not able to easily cross the hydrophobic plasma membrane lipid bilayer, it accumulates in the cell interior leading to increased oxidative stress and turgor pressure, among other effects $[3,9]$. To counteract these effects, the plasma membrane multidrug resistance (MDR) transporters of the Major Facilitator Superfamily (MFS) Tpo2 and Tpo3 were hypothesized to play a role in the extrusion of acetate from acetic acid-challenged S. cerevisiae cells [5]. To date, no acetate export system was described in Z. bailii. S. cerevisiae response to acetic acid-induced stress involves several transcriptional regulators $[4,9]$. The expression of the transcription factor encoding gene $H A A 1$ was found to markedly decrease the duration of the adaptation period of a yeast cell population suddenly exposed to toxic concentrations of acetic acid, by decreasing the loss of cell viability that occurs during this phase of growth latency [5]. Haa1 is considered one of the key players in the control of $S$. cerevisiae response to acetic acid due to its role in the direct, or indirect, regulation of approximately $80 \%$ of acetic acid-responsive genes [6], several of them required for maximal tolerance to acetic acid [8]. These genes code for protein kinases, MDR transporters, transcription factors and proteins involved in lipid metabolism and nucleic acid processing [6].

In order to identify determinants of $Z$. bailii tolerance to acetic acid at the genome level we used in this study a genomic library previously prepared from the highly acetic acid tolerant strain ISA1307, an interspecies hybrid between $Z$. bailii and a closely related species which was isolated from a continuous production plant of sparkling wine $[14,15]$. This genomic library was used to rescue the high susceptibility phenotype of $S$. cerevisiae BY4741_haa1D. This mutant, deleted for HAA1 gene, was chosen due to its very high susceptibility to acetic acid to avoid the use of the much higher concentrations required to inhibit the parental strain growth. With this approach we also expected to identify the functional homologue of S. cerevisiae HAA1 gene in this hybrid strain. During the development of this study, our laboratory carried out the genome sequencing, assembly and annotation of ISA1307 [14]. This hybrid strain has been on the focus of several physiological studies, some 
of them aiming at the understanding of the mechanisms underlying its remarkable intrinsic resistance to acetic acid. Differently from S. cerevisiae, the Z.bailii-derived hybrid strain ISA1307 co-consumes glucose and acetic acid when cultivated in glucose medium supplemented with a sublethal growth inhibitory concentration of acetic acid [16, 17]. Quantitative proteomic studies on the adaptive response of this strain indicate that in glucose and acetic acid cultures the acid is channelled through the TCA cycle [16]. After glucose exhaustion, acetic acid being present as the sole carbon source, the content of several proteins involved in gluconeogenesis and pentose phosphate pathway was however found to increase [16].

The screening of ISA1307 genomic library for genes required for tolerance to acetic acid successfully pointed out several strong candidates, but since this is a hybrid strain difficult to be genetically manipulated, in order to confirm the role of the selected genes in acetic acid tolerance we have explored another strain, $Z$. bailii IST302. This strain was isolated from spontaneous fermentation of wine must and, contrarily to ISA1307 and Z. bailii CLIB213 ${ }^{\mathrm{T}}$ [18], does not flocculate and proved to be more susceptible to genetic engineering than these reference strains. The genome of $Z$. bailii IST302 was recently sequenced and annotated in our laboratory (unpublished data), rendering possible the work here reported.

The knowledge gathered during the present study was based on the expression of ISA1307 genomic library in $S$. cerevisiae, the availability of the genome sequences of the hybrid strain ISA1307 and Z. bailii IST302 and the expression of selected ISA1307 and IST302 gene sequences in $S$. cerevisiae and $Z$. bailii strains and led to the identification of a number of $Z$. bailii genes involved in tolerance to acetic acid. Strong candidates for determinants of acetic acid tolerance in $Z$. bailii or S. cerevisiae are here proposed.

\section{Results}

Selection of S. cerevisiae transformants with increased tolerance to acetic acid through the expression of an ISA1307 genomic library

To search for genes involved in the remarkable tolerance to acetic acid in a $Z$. bailii-related strain we looked for suppressors of the susceptibility phenotype of $S$. cerevisiae BY4741_haa1s through the transformation of this strain with a previously constructed genomic library from the highly tolerant $Z$. bailii-derived interspecies hybrid strain ISA1307 [15]. This allowed the isolation of 1225 yeast clones, selected in a minimal medium without uracil (Fig. 1). These yeast transformants were screened for their increased tolerance to acetic acid through growth in liquid medium in 96-well microplates. This selection methodology allowed the identification of 92 potential candidates out of the 1225 positive colonies initially obtained. Total DNA was extracted from each selected transformant and used to transform Escherichia coli XL1Blue in order to isolate the plasmid insert of interest and to guarantee the identification of a single plasmid capable of suppressing $S$. cerevisiae haald susceptibility phenotype. The plasmids were extracted from E.coli transformants, purified and used to transform again the deletion mutant $S$. cerevisiae BY4741_haa1D and also the parental strain BY4741. Out of these 92 tested transformants, only 31 DNA inserts were confirmed to substantially increase the haa1s mutant tolerance to acetic acid and were hence sequenced. Both the parental and the deletion mutant haa1s cells transformed with each one of these 31 plasmids were grown in 96-well microplates with $60 \mathrm{mM}$ of acetic acid supplemented medium or in control conditions in order to confirm the ability of the corresponding inserts to rescue the haa1s mutant susceptibility phenotype as well as their effect in the growth of the parental strain transformants (Additional file 1: Figure S1). Considering the haa1s transformants, the suppressors were able to rescue haa1s susceptibility phenotype by shortening the latency period by at least $20 \mathrm{~h}$ when compared with the haa1s strain transformed with the empty vector. At the concentration of acetic acid tested $(60 \mathrm{mM}$, pH4.0) the protective effect of the expression of the DNA inserts in the candidate clones was not as evident for the parental strain compared with the haa1s mutant, since the parental strain is much less susceptible than the mutant to acetic acid. Nevertheless, a number of inserts clearly improve the tolerance of the parental strain transformed with the empty vector at the acetic acid concentration tested. Results obtained with the five best suppressors, or in other words those capable of diminishing at a greater extent the duration of the latency period of the parental or the haa $1 \Delta$ strains transformed with the empty vector, are shown in Fig. 2a and b. Three of these suppressors, the inserts B02, B18 and S06, were identified by the transformation of both the parental and the haal deletion mutant strains.

\section{In silico analysis of ISA1307 genomic DNA fragments} whose expression was found to be required for increased acetic acid tolerance in $S$. cerevisiae

The in silico analysis of the 31 selected genomic DNA fragments from the $Z$. bailii-derived interspecies hybrid strain ISA1307 led to the identification of a number of ORFs which are putative candidate determinants of tolerance to the acid. Since we found that the expression of 


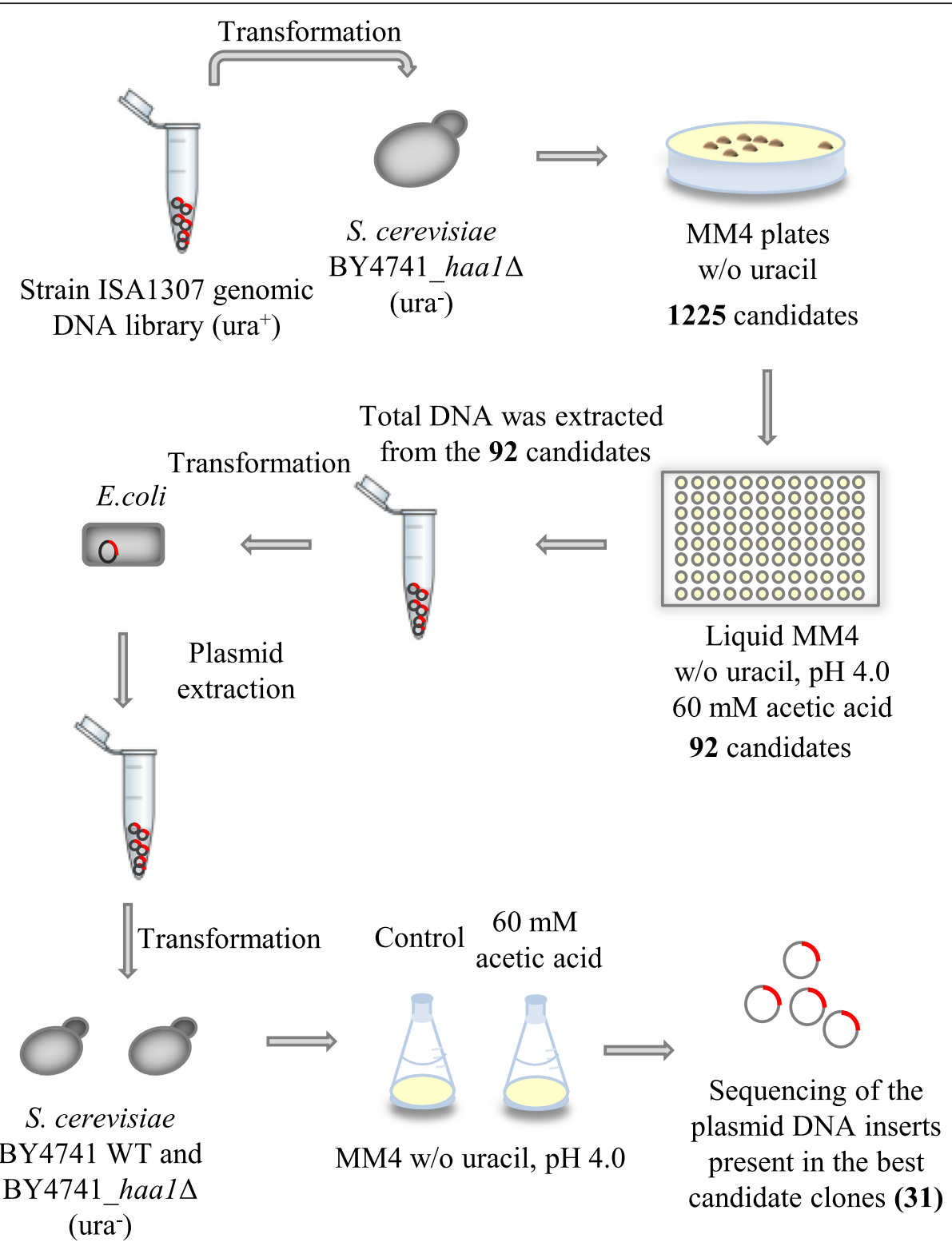

Fig. 1 Genomic library screening to search for determinants of acetic acid tolerance in the strain ISA1307. Schematic representation of the screening of the Z. bailii-derived interspecies hybrid strain ISA1307 genomic library carried out in this study to search for determinants of acetic acid tolerance, able to rescue the susceptibility phenotype of S. cerevisiae BY4741_haalA

DNA inserts containing only one putative truncated ORF also led to the increase of haals tolerance to acetic acid, the incomplete ORFs were also considered for further analysis and the presence of conserved functional domains in the identified inserts was investigated. However, the truncated ORFs comprising less than $15 \%$ of the complete sequence, which contained limited portions of conserved domains or no conserved domains, were disregarded at this phase, resulting in the selection of 32 complete and 33 truncated putative candidate ORFs (Additional file 2).
ORFs with homology to S. cerevisiae genes

For each ISA1307 selected ORF, the predicted S. cerevisiae homologous gene and the corresponding functional description were gathered (Additional file 2). References to previous studies in which the deletion of the gene was already described as leading to an increase or decrease of yeast susceptibility to acetic acid or other weak acids are also indicated. Since the strain ISA1307 is an interspecies hybrid between $Z$. bailii and a closely related species [14], Additional file 2 also includes information regarding the nucleotide 

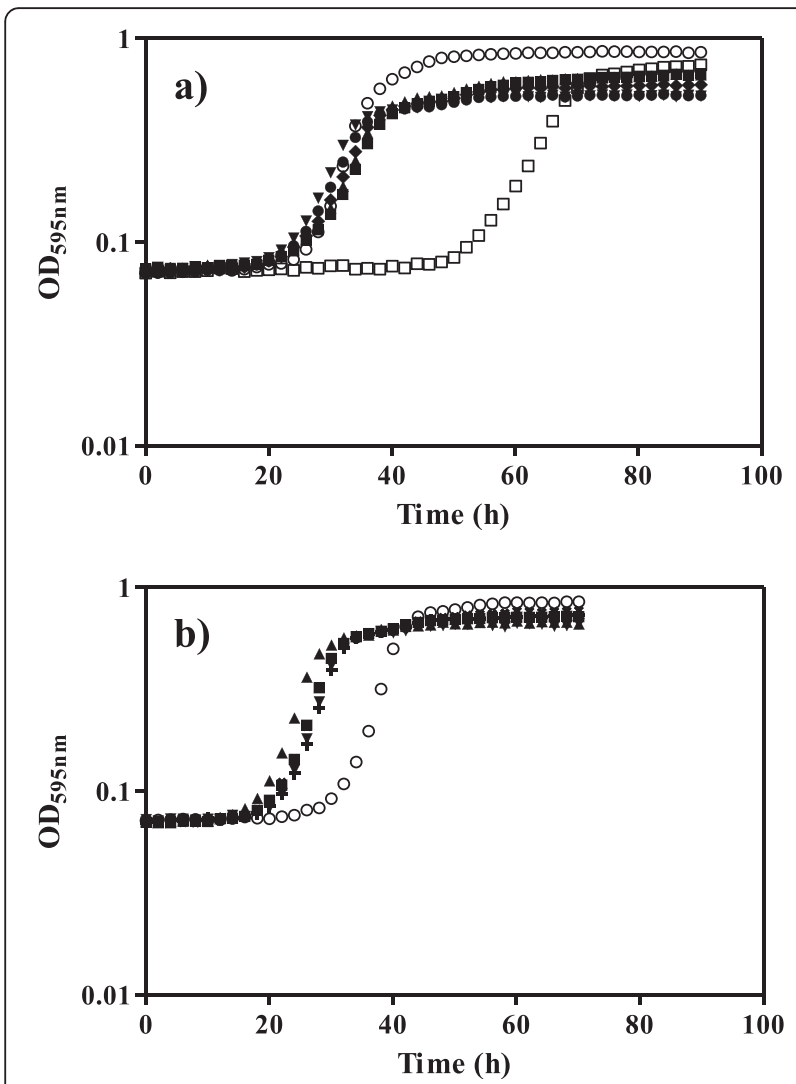

Fig. 2 Growth curves of the best strains considering acetic acid tolerance obtained by transformation of S. cerevisiae BY4741_haa1 $\Delta$ and BY4741 parental with ISA1307 genomic library plasmids. a S. cerevisiae BY4741_haa1 $\Delta$ transformed with the empty vector ( $\square$ ) and with plasmids holding DNA fragments from the strain ISA1307

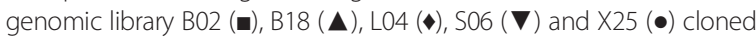
in vector pRS316. S. cerevisiae BY4741 parental strain transformed with the empty vector (o) was included in the same 96-well microplate as a positive control. b S. cerevisiae BY4741 parental strain transformed with the empty vector (O) or with plasmids containing DNA fragments from

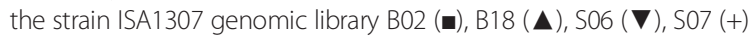
and W08 $(X)$. The selected strains were those with a significant decreased duration of the latency period of the deletion mutant or in the parental strain when compared with the corresponding strain containing the empty vector. The growth curves were performed in MM4 medium ( $\mathrm{pH}$ 4.0) without uracil, supplemented with $60 \mathrm{mM}$ acetic acid (pH 4.0) and are representative of at least three independent growth assays that gave rise to similar growth curves

sequence identity of each ORF present in the different DNA inserts with $Z$. bailii CLIB213 ${ }^{\mathrm{T}}$ genome [18] to identify the ORFs that likely are from $Z$. bailii. Interestingly, about one half of the selected DNA inserts that were able to rescue the haa1s mutant susceptibility phenotype to acetic acid is, presumably, derived from the parental $Z$. bailii species (99-100\% identity with $\mathrm{CLIB}_{213^{\mathrm{T}}}$ genome) while the other half is, apparently, derived from the other yeast species closely related to Z. bailii (93-98\% identity with CLIB213 ${ }^{\mathrm{T}}$ genome).
ORFs with no homology with S. cerevisiae genes

For 7 out of the 65 ORFs identified amongst the ISA1307 genomic DNA fragments resulting from the screening, no homology with $S$. cerevisiae genes could be found. In order to obtain additional information that could support the elucidation of their possible function and contribution to confer protection against acetic acid in the S. cerevisiae haa1s mutant, a prediction of conserved functional domains [19] and transmembrane helices (http://www.cbs.dtu.dk/services/TMHMM/) was attempted. The information gathered for these ORFs is summarised in Table 1 that also includes the detected similarities with other organisms (using the PEDANT database). The DNA inserts E13 and S06, each one holding two complete ORFs, were considered to deserve further attention. The ORF ZBAI_09903 from the E13 DNA insert has homology with pyruvate decarboxylases from different organisms and contains a pyrimidine binding domain (PYR) that can be found in many key metabolic enzymes. The DNA insert E13 also contains the ORF ZBAI_09904 whose encoded protein has a domain characteristic of DNA and RNA helicases, but shows weak similarities with yeast helicases. Moreover, the two ORFs present in the insert S06, which was found to be the best suppressor of the acetic acid susceptibility phenotype of mutant haa1 $\Delta$ and among the best five genomic library inserts whose expression led to increased tolerance to acetic acid in the parental strain, encode two putative membrane proteins. Specifically, ZBAI_02295 holds a domain associated with the DUP family of proteins of unknown function that were suggested to be involved in membrane trafficking processes [20] and ZBAI_02296 contains a PRK15313 domain related to autotransport proteins. Both ORFs have homologues in $Z$. rouxii. These observations reinforce the idea that at least one of these two ORFs is a strong candidate to be considered as a determinant of acetic acid tolerance. Given the apparent relevance of the insert S06 and to test the proposed hypothesis, the individual subcloning of these two ORFs was performed.

The ORF ZBAI_02295 is required for tolerance to acetic acid The two ORFs present in S06 genomic library DNA insert were subcloned by homologous recombination in the expression vector pGREG506 containing a galactose inducible promoter (GAL1) and then expressed in both S. cerevisiae BY4741_ haa1D and parental background strains to search for increased tolerance to acetic acid. The heterologous expression of pGREG506_ZBAI_02295 in haa $1 \Delta$ mutant strain was found to lead to a considerable increase of tolerance to acetic acid up to the level of the parental strain with the empty plasmid, with a pronounced decrease in the duration of the latency phase and an increase in the specific growth rate compared with control cells (Fig. 3). This effect was barely detected when the parental strain was used as host cell, even 
Table 1 Genomic DNA inserts from strain ISA1307 genomic library required for acetic acid tolerance containing the putative ORFs for which weak or no homology with S. cerevisiae genes was found. Information about other ORFs present in the same DNA insert is provided, as well as the best blast hits and the predicted functional and transmembrane domains of the corresponding protein

\begin{tabular}{|c|c|c|c|c|c|}
\hline $\begin{array}{l}\text { DNA } \\
\text { insert }\end{array}$ & $\mathrm{ORF}^{\mathrm{a}}$ & $\begin{array}{l}\text { ORFs in the } \\
\text { same insert }\end{array}$ & Best blast hits & Functional domains & $\begin{array}{l}\text { Transmembrane } \\
\text { domains }\end{array}$ \\
\hline \multirow[t]{3}{*}{$\begin{array}{l}3.13 \\
(4069 \mathrm{bp})\end{array}$} & \multirow[t]{3}{*}{$\begin{array}{l}\text { ZBAl_06221 } \\
(40 \%)\end{array}$} & $\begin{array}{l}\text { ZBAI_06218 } \\
(47 \%)\end{array}$ & \multirow{3}{*}{$\begin{array}{l}\text { Glutathione S-transferase from Macrophomina } \\
\text { phaseolina (charcoal rot fungus) and putative } \\
\text { uncharacterized proteins from Torulaspora } \\
\text { delbrueckii and several fungi. }\end{array}$} & \multirow{3}{*}{$\begin{array}{l}\text { Domains related with the Glutathione S- } \\
\text { transferase family. In particular, the portion } \\
\text { which is present in the DNA library frag- } \\
\text { ment possesses a C-terminal alpha helical } \\
\text { domain of the GST family. }\end{array}$} & \multirow[t]{3}{*}{-} \\
\hline & & ZBAI_06219 & & & \\
\hline & & ZBAI_06220 & & & \\
\hline \multirow[t]{3}{*}{$\begin{array}{l}18.9 \\
(4511 \mathrm{bp})\end{array}$} & \multirow[t]{3}{*}{ ZBAI_03403 } & $\begin{array}{l}\text { ZBAI_03401 } \\
(28 \%)\end{array}$ & \multirow{3}{*}{$\begin{array}{l}\text { Two putative uncharacterised proteins, one } \\
\text { from } Z \text {. rouxii and the other from } T \text {. } \\
\text { delbrueckii. }\end{array}$} & \multirow[t]{3}{*}{-} & \multirow[t]{3}{*}{-} \\
\hline & & ZBAI_03402 & & & \\
\hline & & $\begin{array}{l}\text { ZBAI_03404 } \\
(30 \%)\end{array}$ & & & \\
\hline \multirow[t]{2}{*}{$\begin{array}{l}\text { E13 } \\
\text { (4470 bp) }\end{array}$} & ZBAI_09903 & ZBAI_09904 & $\begin{array}{l}\text { Putative and described pyruvate } \\
\text { decarboxylases from other yeasts and } \\
\text { several other different organisms. }\end{array}$ & $\begin{array}{l}\text { Pyrimidine binding domain (PYR) of } \\
\text { pyruvate decarboxylase. }\end{array}$ & - \\
\hline & ZBAI_09904 & ZBAI_09903 & $\begin{array}{l}\text { Weak similarities with several helicase-like } \\
\text { proteins encoded by the } \mathrm{Y}^{\prime} \text { element of } \\
\text { subtelomeric regions from S. cerevisiae } \\
\text { and S. kudriavzevii. }\end{array}$ & $\begin{array}{l}\text { Domain characteristic from DNA and RNA } \\
\text { helicases. }\end{array}$ & - \\
\hline \multirow[t]{2}{*}{$\begin{array}{l}\text { S06 } \\
\text { (4413 bp) }\end{array}$} & ZBAI_02295 & ZBAI_02296 & $\begin{array}{l}\text { Similarities with hypothetical proteins from } \\
\text { Z. rouxii, most of them being } \\
\text { uncharacterised and others sharing some } \\
\text { homology with membrane proteins from } \\
\text { DUP240 and DUP380 gene families, such as } \\
\text { COS8, COS9 and YHLO44W. }\end{array}$ & $\begin{array}{l}\text { Domain related with DUP family, which } \\
\text { consists of several yeast proteins of } \\
\text { unknown functions. }\end{array}$ & 1 \\
\hline & ZBAI_02296 & ZBAI_02295 & $\begin{array}{l}\text { Weak similarities with several hypothetical } \\
\text { proteins from } Z \text {. rouxii which present no } \\
\text { similarity with proteins from other species. }\end{array}$ & $\begin{array}{l}\text { PRK15313 domain related to autotransport } \\
\text { protein MisL (provisional). }\end{array}$ & 4 \\
\hline $\begin{array}{l}\text { V14 } \\
\text { (2907 bp) }\end{array}$ & ZBAI_09508 & $\begin{array}{l}\text { ZBAI_09509 } \\
(99 \%)\end{array}$ & $\begin{array}{l}\text { Putative uncharacterised proteins mainly } \\
\text { from other yeasts, such as } Z \text {. rouxii, } T \text {. } \\
\text { delbrueckii and Lachancea thermotolerans } \\
\text { species, and fungi. }\end{array}$ & Zinc-finger related domains. & - \\
\hline
\end{tabular}

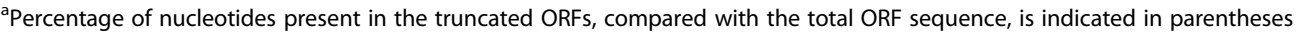

though we have used increased concentrations of acetic acid $(65$ and $70 \mathrm{mM})$ in order to obtain an inhibitory effect equivalent to the one observed in the mutant haa1s (results not shown). On the other hand, the expression of the ORF ZBAI_02296 caused an increase in the duration of the lag phase for both strains (Fig. 3), which indicates that it can be harmful in the context of acetic acid tolerance. For control purposes, Fig. 3 also shows the growth curves of both strains transformed with pGREG506 or pGREG506_noHIS3, that is the same cloning vector but with the HIS3 gene, controlled by the GAL1 promoter, removed. This new construction was needed to prepare the correct controls since the recombinant plasmids lose the HIS3 gene active mark and also because the auxotrophy of the host cells (his ${ }^{-}$) implicates an alteration of the acetic acid tolerance depending on histidine availability. Although in the case of the parental strain the removal of the HIS3 gene from the expression vector had no detectable implications in the growth curve of the transformed cells, the expression of this gene in haa $1 \Delta$ cells confers a significant advantage when acetic acid is present. Therefore pGREG506_noHIS3 plasmid was considered the correct empty cloning vector to be used to transform the control cells.

The results of the expression experiments support the idea that the ORF ZBAI_02295 should be considered as a strong candidate determinant of tolerance to acetic acid in strain ISA1307. On the contrary, the expression of ORF ZBAI_02296 had a negative effect in S. cerevisiae tolerance to acetic acid and for this reason it was not considered as a candidate determinant.

\section{Selection of strong candidate determinants of acetic acid tolerance}

The next step was to narrow down the list of the remaining 63 selected ORFs in an attempt to identify the most promising candidate genes for determinants of tolerance to acetic acid. Although all the selected ORFs are potential candidates, it is essential to understand the relevance of each one when several ORFs are present in the same insert. Due to the difficult genetic engineering of Zygosaccharomyces genus in general, and of the 


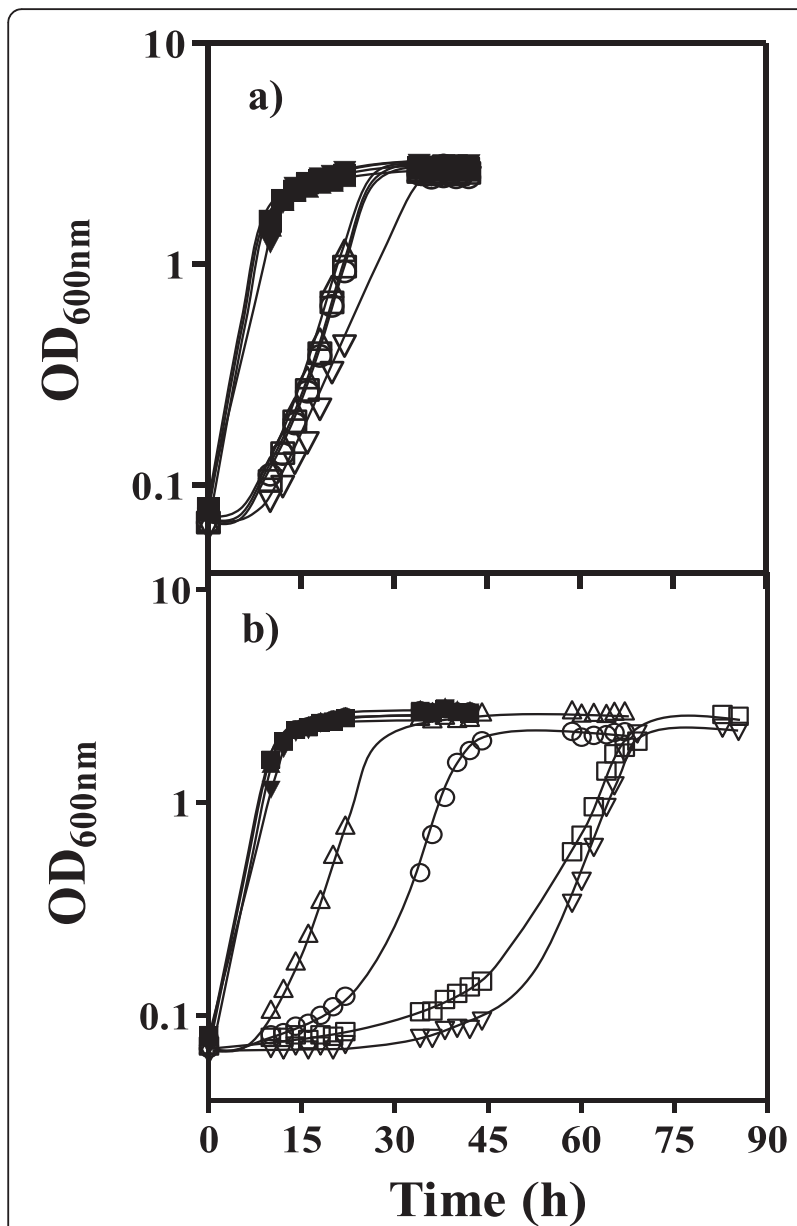

Fig. 3 Effect of the expression of ZBAI_02295 or ZBAI_02296 in S. cerevisiae parental strain BY4741 and derived deletion mutant haa1 $\Delta$. Growth curves of S. cerevisiae BY4741 parental (a) and haa1D (b) strains transformed with pGREG506_ZBAI_02295 $(\Delta, \mathbf{\Delta})$ pGREG506_ZBAI_02296 $(\nabla, \boldsymbol{\nabla})$, pGREG506_noHIS3 $(\square, \boldsymbol{\square})$ and pGREG506 $(0, \bullet)$. Growth was performed in MM4 medium ( $\mathrm{pH}$ 4.0) without uracil and containing $1 \%(\mathrm{w} / \mathrm{v})$ galactose, supplemented with $60 \mathrm{mM}$ acetic acid (open symbols) and in the same conditions without acetic acid (closed symbols). The growth curves are representative of at least three independent growth assays that gave rise to similar results

ISA1307 hybrid strain in particular, no deletion mutant could be constructed and, consequently, the direct confirmation of the role of each putative candidate ORF in acetic acid tolerance in this specific strain was limited. Therefore, the selection of strong candidate determinants of acetic acid tolerance among the ORFs present in each DNA insert able to rescue the susceptibility phenotype of the S. cerevisiae haa1 $\Delta$ mutant was based on the presumption that sole ORFs present in DNA inserts that were able to suppress the acetic acid susceptibility phenotype of haa1 $\Delta$ are the cause of the increased tolerance. Some of these ORFs homologues were already mentioned as contributing to $S$. cerevisiae tolerance to acetic acid and/or other weak acids, supporting the criterion used. The list of inserts containing the strong candidate determinants of acetic acid tolerance selected during this work is presented in Table 2 (a selection from Additional file 2). The strong candidate determinants of tolerance, according to the mentioned criterion, are represented in bold in both Table 2 and Additional file 2. The ORF ZBAI_02295, whose role in acetic acid tolerance was confirmed by subcloning experiments, is also included. It is important to refer that the expression of truncated ORFs was found to apparently confer tolerance to acetic acid, given that this was observed when a single incomplete ORF was present in the insert. This is for example the case of S. cerevisiae truncated MSN4 and WSC4 homologues that are present in the DNA inserts B02 and 23.1, respectively. For the inserts where several complete and/or truncated ORFs are present it is not possible, at this phase, to decide which of the various ORFs is indeed involved in conferring increased tolerance to acetic acid without the subcloning and functional expression of each single ORF. Nevertheless, previous reports from the literature on the role of a considerable number of these ORFs in S. cerevisiae tolerance to weak acids provide good indications of where to start.

In summary, and taking into account the aforementioned criterion, the following S. cerevisiae gene homologues were selected and proposed herein as strong candidate determinants of acetic acid tolerance in the strain ISA1307: GYP8 and WSC4 (cellular transport and transport routes), PMT1, KTR7 and RKR1 (protein fate), TIF3 (protein synthesis), ILV3 (amino acid metabolism) and MSN4 (transcription).

\section{Complementation of acetic acid susceptibility of $S$. cerevisiae mutants deleted for genes homologous to ISA1307 tolerance candidate genes}

In order to confirm the hypothesized role of the strong candidate determinants of acetic acid tolerance proposed, plasmids from ISA1307 genomic library containing a single complete or incomplete ORF were expressed in the haploid S. cerevisiae mutant lacking the corresponding homologous gene (Fig. 4). The expression of the library plasmids containing GYP8, KTR7, MSN4 or WSC4 homologues was confirmed to rescue the acetic acid susceptibility phenotype of the corresponding S. cerevisiae deletion mutant. Specifically, an increase of the maximum specific growth rate was clearly observed when these library plasmids were individually expressed, as well as a reduction of the duration of the latency period even when compared with the parental strain carrying the empty plasmid. Although the expression of the TIF3 homologue in 
Table 2 Genomic DNA inserts from strain ISA1307 genomic library containing the strong candidate determinants of tolerance to acetic acid proposed in this work

\begin{tabular}{|c|c|c|c|c|c|c|c|}
\hline $\begin{array}{l}\text { DNA } \\
\text { insert }\end{array}$ & $\mathrm{ORF}^{\mathrm{a}}$ & $\begin{array}{l}\text { Identity } \\
\text { (\%) with Z. } \\
\text { bailii } \\
\text { CLIB213 }^{\text {Tb }}\end{array}$ & $\begin{array}{l}\text { S.cerevisiae } \\
\text { putative } \\
\text { homologue }\end{array}$ & $\begin{array}{l}\text { Identity } \\
\text { (\%) with } \\
\text { S. } \\
\text { cerevisiae }^{c}\end{array}$ & $\begin{array}{l}\text { Size (aa) } \\
\text { ISA1307 / S. } \\
\text { cerevisiae / }^{\text {Alignment }}\end{array}$ & S.cerevisiae function ${ }^{\mathrm{e}}$ & $\begin{array}{l}\text { Alteration in yeast } \\
\text { deletion mutant } \\
\text { susceptibility to weak } \\
\text { organic acids }^{f}\end{array}$ \\
\hline $\begin{array}{l}\mathbf{8 . 2 3} \\
\text { (2782 bp) }\end{array}$ & ZBAI_05695 & 99 & GYP8 & 34.0 & $\begin{array}{l}556 / 497 / \\
503\end{array}$ & $\begin{array}{l}\text { GTPase-activating protein involved in the } \\
\text { regulation of ER to Golgi vesicle transport } \\
\text { Cellular transport and transport routes }\end{array}$ & - \\
\hline
\end{tabular}

$\begin{array}{llllll}\mathbf{1 8 . 2 2} & \text { ZBAI_04770 } & \mathbf{9 5 / 9 5} & \text { PMT1 } & 66.9 & 761 / 817 \text { / } \\ \begin{array}{l}\text { (2803 bp) } \\ (41 \%)\end{array} & & & & 746 \\ \mathbf{2 3 . 1} & \text { ZBAI_09707 } & \mathbf{9 2 / 9 5} & \text { WSC4 } & 29.1 & 854 / 605 / \\ (2277 \text { bp) } & \begin{array}{l}(40 \%) \\ \text { (40 })\end{array} & & & & 632\end{array}$

Protein O-mannosyltransferase

Acetic acid (S) [8]

Protein fate

ER membrane protein involved in the translocation of soluble secretory proteins and insertion of membrane proteins into the ER membrane; may also have a role in the stress response

\section{Cellular transport and transport routes}

$\begin{array}{llllll}\mathbf{2 3 . 1 7} & \text { ZBAl_09663 } & \mathbf{9 9 / 9 9} & \text { ILV3 } & 82.5 & 583 / 585 / \\ (1812 \text { bp) } & (66 \%)\end{array} \quad \begin{array}{ll}584\end{array}$

Dihydroxyacid dehydratase, catalyzes third step in the common pathway leading to biosynthesis of branched-chain amino acids

\section{Amino acid metabolism}

\begin{tabular}{|c|c|c|c|c|c|c|}
\hline \multirow[t]{2}{*}{$\begin{array}{l}\text { B02 } \\
\text { (3640 bp) }\end{array}$} & $\begin{array}{l}\text { ZBAI_03527 } \\
(77 \%)\end{array}$ & $95 / 95$ & MSN4 & 32.9 & $\begin{array}{l}574 / 630 / \\
590\end{array}$ & $\begin{array}{l}\text { Transcriptional activator that regulates the } \\
\text { general stress response of } S \text {. cerevisiae }\end{array}$ \\
\hline & & & & & & Transcription \\
\hline \multirow{2}{*}{$\begin{array}{l}\text { B18 } \\
\text { (2917 bp) }\end{array}$} & \multirow{2}{*}{ ZBAI_01028 } & \multirow[t]{2}{*}{94} & \multirow[t]{2}{*}{ TIF3 } & \multirow[t]{2}{*}{55.8} & \multirow{2}{*}{$\begin{array}{l}433 / 436 / \\
453\end{array}$} & Translation initiation factor elF- $4 \mathrm{~B}$ \\
\hline & & & & & & Protein synthesis \\
\hline \multirow[t]{2}{*}{$\begin{array}{l}\text { S07 } \\
\text { (2860 bp) }\end{array}$} & \multirow[t]{2}{*}{$\begin{array}{l}\text { ZBAI_05420 } \\
(57 \%)\end{array}$} & \multirow[t]{2}{*}{$95 / 95$} & \multirow[t]{2}{*}{ KTR7 } & \multirow[t]{2}{*}{49.3} & \multirow[t]{2}{*}{$\begin{array}{l}514 / 517 / \\
525\end{array}$} & $\begin{array}{l}\text { Putative mannosyltransferase involved in } \\
\text { protein glycosylation }\end{array}$ \\
\hline & & & & & & Protein fate \\
\hline \multirow{2}{*}{$\begin{array}{l}\text { S06 } \\
(4413 \text { bp) }\end{array}$} & ZBAI_02295 & 99 & - & - & $178 /-/-$ & - \\
\hline & ZBAI_02296 & 98 & - & - & $261 /-/-$ & - \\
\hline $\begin{array}{l}\text { Y08 } \\
\text { (2104 bp) }\end{array}$ & $\begin{array}{l}\text { ZBAI_01926 } \\
(34 \%)\end{array}$ & $92 / 93$ & $R K R 1$ & 48.8 & $\begin{array}{l}1555 / 1562 / \\
1571\end{array}$ & $\begin{array}{l}\text { RING domain E3 ubiquitin ligase; involved in } \\
\text { the ubiquitin-mediated degradation of non- } \\
\text { stop proteins }\end{array}$ \\
\hline
\end{tabular}

2,4-D (S) [41]

Acetic acid (S) [42] Propionic acid (S) [7]

Protein fate

\footnotetext{
${ }^{a}$ Percentage of nucleotides present in the truncated ORFs, compared with the total ORF sequence, is indicated in parentheses

${ }^{\mathrm{b}}$ Identity (\%) between each ORF found in the DNA inserts and Z. bailii CLIB213 ${ }^{\top}$ genome was obtained using BLAST analysis (http://blast.ncbi.nlm.nih.gov/Blast.cgi) 'Identity (\%) between ISA1307 and S. cerevisiae S288C homologous genes was retrieved from PEDANT database (http://pedant.helmholtz-muenchen.de/genomes.jsp?Category=fungal)

${ }^{d}$ Identity (\%) between homologous proteins from ISA1307 and S. cerevisiae. The size of the proteins and their pairwise alignment, given by the number of amino acid residues (aa), was retrieved from the PEDANT database (http://pedant.helmholtz-muenchen.de/genomes.jsp?Category=fungal)

'The putative function of each ORF was assigned based on the function of each S. cerevisiae homologous gene (www.yeastgenome.org). The functional category is provided in bold

fList of the studies involving the S. cerevisiae corresponding deletion mutant susceptibility or resistance phenotypes under weak acid stress (S) - the single deletion mutant is susceptible to the acid; $(\mathrm{R})$ - the single deletion mutant is resistant to the acid
}

the corresponding library plasmid also decreased the duration of the latency period in S. cerevisiae tif3 $\Delta$, it did not fully complement the high acetic acid susceptibility phenotype of tif $3 \Delta$ up to the parental strain level. Since at the concentration of acetic acid used in the complementation experiments $S$. cerevisiae BY4741_rkr1 $1 \Delta$ is mildly susceptible to acetic acid, the effect of the expression in this mutant of the RKR1 homologue in the duration of the latency phase in the presence of acetic acid was barely detected. The expression of the library plasmid containing the essential ILV3 homologous gene in the diploid strain S. cerevisiae BY4743 lacking a copy of ILV3 gene also led to the decrease of the duration of the latency phase of both ilv3s and parental strains. In the case of pmt1s, a slight complementation of the susceptibility phenotype was achieved with the expression of the corresponding genomic library plasmid.

As previously mentioned, when expressed in the yeast host cell the inserts containing MSN4 and TIF3 homologues were among the best suppressors of the acetic acid susceptibility phenotype of haa1s mutant, also 

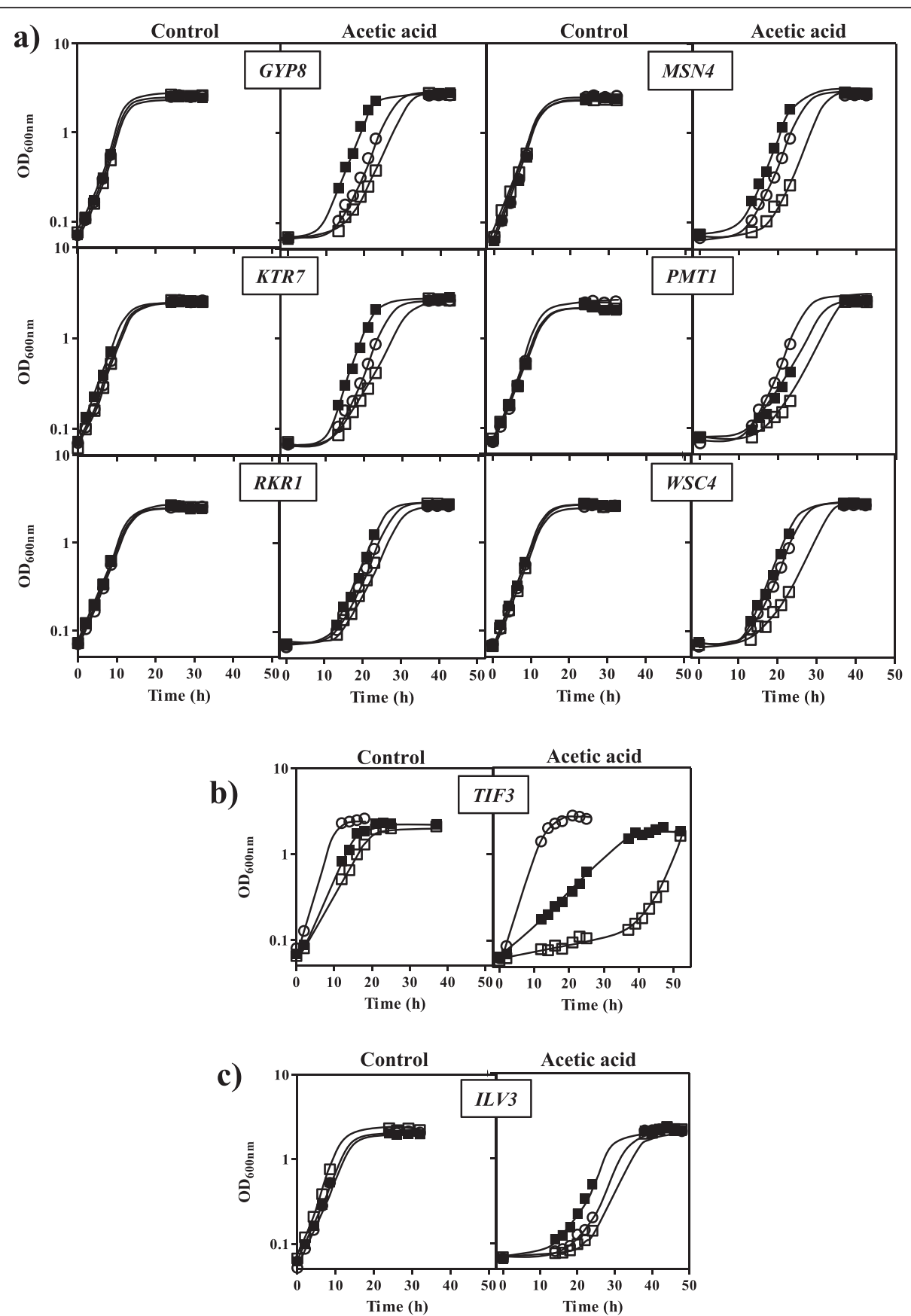

Fig. 4 Expression of ISA1307 genomic library plasmids containing a single ORF in S. cerevisiae mutants deleted for the corresponding homologous gene. Growth curves of $S$. cerevisiae mutants gyp $8 \Delta, k \operatorname{tr} 7 \Delta, r k r 1 \Delta, m s n 4 \Delta, p m t 1 \Delta$, ws $44 \Delta$, tif3 $\Delta$ and ilv3 $\Delta$ transformed with the corresponding plasmid from the strain ISA1307 genomic library, specifically 8.23, S07, Y08, B02, 18.22, 23.1, B18 and 23.17, respectively, which contained the putative ISA1307 homologue of the $S$. cerevisiae gene deleted in each mutant ( $\mathbf{\square}$ ) or with the empty vector (口). Strains were cultivated in MM4 medium (pH 4.0) without uracil or in this same basal medium supplemented with $60 \mathrm{mM}$ (a), $40 \mathrm{mM}$ (b) and $65 \mathrm{mM}$ (c) of acetic acid. S. cerevisiae BY4741 and BY4743 parental strains were also transformed with the empty vector (o) for control purposes. The growth curves shown are representative of three independent assays

leading to a remarkable increase of acetic acid tolerance in the parental strain. Given that the role of these genes in the context of $S$. cerevisiae tolerance to weak acids was already reported in literature, they were selected for further experiments.
Expression of Z. bailii genes ZbMSN4 and ZbTIF3 in Z. bailii and $S$. cerevisiae strains

The involvement of $Z$. bailii MSN4 homologue in acetic acid tolerance was investigated based on the expression of this gene in S. cerevisiae BY4741 parental and derived 
deletion mutant msn4A, and in S. cerevisiae W303-1A parental and derived double deletion mutant $m s n 2 \Delta m s n 4 \Delta$ strains (Fig. 5). Since ISA1307 hybrid genome contains two copies of the MSN4 homologue that have similar $5^{\prime}$ and $3^{\prime}$ ends, it would be very difficult to amplify only the desired $Z$. bailii copy and for this reason strain Z. bailii IST302 was used to amplify the MSN4 homologue ZbMSN4. Results of this heterologous expression show that ZbMSN4 under the control of S. cerevisiae MSN4 promoter increases the tolerance of the parental $S$. cerevisiae strains BY4741 and W303-1A and derived deletion mutant strains $m s n 4 \Delta$ and $m s n 2 \Delta m s n 4 \Delta$. While in W303-1A_msn2 $\Delta m s n 4 \Delta$ strain the expression of ZbMSN4 nearly complemented the acetic acid susceptibility phenotype to the level of the parental strain, in BY4741_msn4A the expression of the gene significantly improved the acetic acid tolerance even above the level of tolerance exhibited by its parental strain, as in the case of the complementation with the library plasmid B02. These results show that IST302 ZbMSN4 under the influence of S. cerevisiae MSN4 promoter in the selected expression vector overcomes the effect of the native S. cerevisiae MSN4 and is effective enough to counteract the lack of the two transcription factors in the double deletion mutant. Extra copies of ZbMSN4 and ZbTIF3 from Z. bailii IST302 were also expressed in this same strain. Results confirm that $Z$. bailii IST302 containing the recombinant vector with the extra copy of either ZbMSN4 or ZbTIF3 is significantly more tolerant to acetic acid in comparison with the host strain with the empty expression vector (Fig. 6).

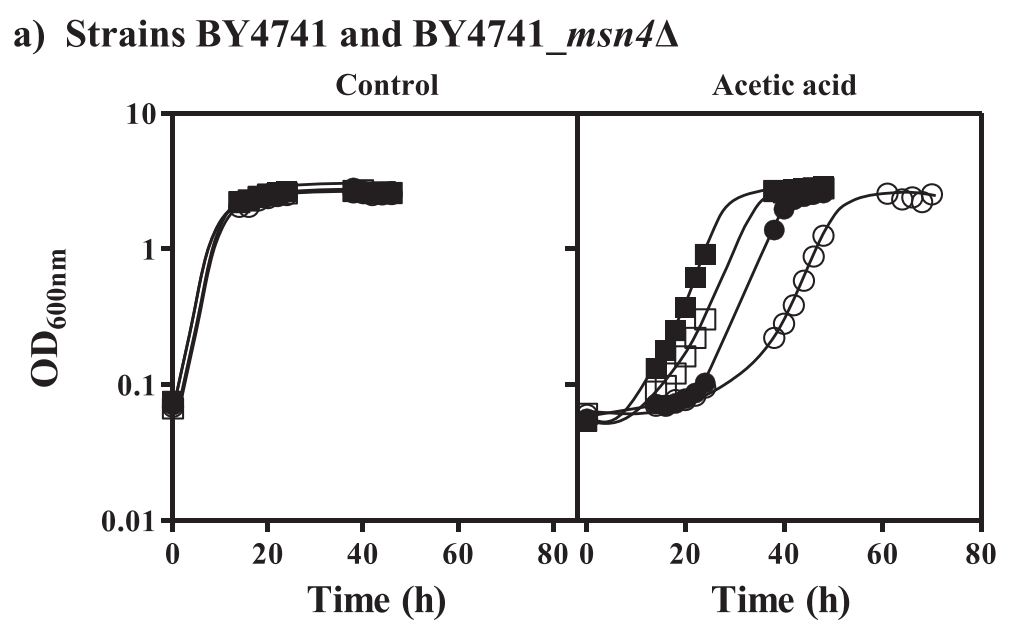

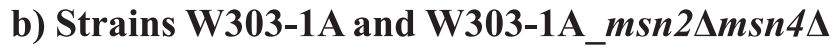

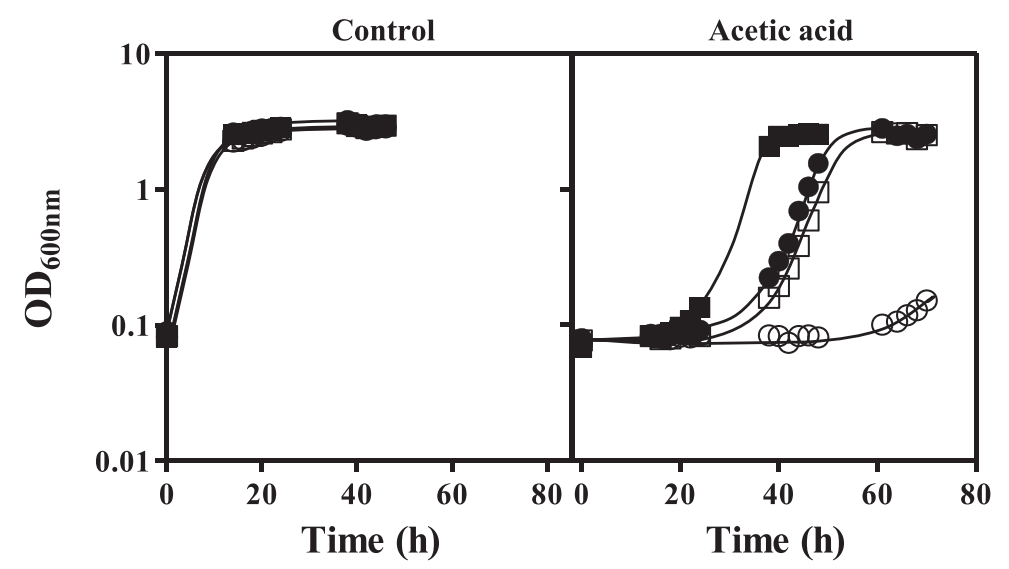

Fig. 5 Effect of the expression of ZbMSN4 in S. cerevisiae strains BY4741 parental and derived deletion mutant msn4A (a) and W303-1A parental and derived double deletion mutant msn2 $\operatorname{msn} 4 \Delta$ (b). Growth curves of S. cerevisiae parental strains BY4741 (a) and W303-1A (b) (filled symbo/s) and the corresponding derived deletion mutants $m s n 4 \Delta$ (a) and $m s n 2 \Delta m s n 4 \Delta$ (b) (empty symbo/s) transformed either with the empty vector $(0, \bullet)$ or with pGREG506_promMSN4Sc_ZbMSN4 (, $\mathbf{\square})$. S. cerevisiae BY4741 background strains were cultivated in MM4 medium (pH 4.0) without uracil or in this same basal medium supplemented with $65 \mathrm{mM}(\mathbf{a})$, and S. cerevisiae W303-1A background strains were cultivated in MM5 medium (pH 4.0) without uracil or in this same basal medium supplemented with $60 \mathrm{mM}(\mathbf{b})$. The growth curves shown are representative of three independent assays 


\section{Discussion}

In order to get clues on the genes/proteins involved in the high intrinsic tolerance to acetic acid of the $Z$. bailiiderived interspecies hybrid strain ISA1307, we have explored a previously constructed genomic library from this strain, as well as the available information on its full genome sequence which was released and annotated during the progress of this study [14]. Considering the experimental design of the screening carried out to search for genes required for maximal tolerance to acetic acid, it was not expected that the identification of ISA1307 HAA1 homologue would fail. Indeed, based on the information retrieved from the PEDANT database, two copies of a putative $H A A 1$-homologue are present in the genome of this hybrid strain (ZBAI_01494 and ZBAI_05761) sharing, respectively, 50 and $47 \%$ identity with $S$. cerevisiae $H A A 1$ nucleotide sequence (pairwise alignment performed at http://www.ebi.ac.uk/Tools/psa/ (European Bioinformatics Institute)). The fact is that when the genomic library used in the screening was constructed [15], it was assumed that the size of ISA1307 genome was similar to the size of $S$. cerevisiae genome (12 Mb). However, following genome sequencing, the genome size of this hybrid strain was found to have approximately $22 \mathrm{Mb}$ [14]. This means that the genomic library tested is poorly representative of the full ISA1307 genome and thus a full functional $H A A 1$ gene sequence may be missing in the library. Also, we cannot exclude at this time the possibility that ISA1307 Haal proteins do not have in this highly acetic acid tolerant strain the important role demonstrated for the $S$. cerevisiae homologue or that the $H A A 1$ homologous genes in this strain are not functional.

The genes emerging from this study derive at similar proportions from each of the two parental strains of the hybrid strain ISA1307. Remarkably, the differences registered in the two alleles of ISA1307, at the nucleotide level, have apparently no impact in the amino acid sequence of the encoded proteins identified in our study as potential determinants of tolerance to acetic acid. In fact, only six gene pairs in ISA1307 whole genome exhibit nucleotide differences (rate of non-synonymous substitutions $(\mathrm{dN})$ and synonymous substitutions $(\mathrm{dS})$ above 1) with an impact in the amino acid sequence of the encoded proteins [14].

The mechanisms behind yeast adaptation and tolerance to weak acids stress are multifactorial [9]. In other words, yeast tolerance does not rely in a single key cellular process, so it would be expectable that the candidate determinants of acetic acid tolerance emerging from this study are related to different functions in cell. Indeed, the genes identified in our screening as strong candidate determinants of acetic acid tolerance in the highly tolerant strain ISA1307 include genes presumably involved in functions such as cellular transport and transport routes, protein fate, protein synthesis, amino acid metabolism and transcription, as detailed below. The ORFs identified in this study that share poor or no homology with $S$. cerevisiae genes should also be considered as relevant, in particular ZBAI_09903 that holds a pyrimidine binding domain of pyruvate decarboxylase required for the conversion of pyruvate into acetaldehyde and ethanol. Interestingly, a pyruvate decarboxylase enzyme, involved in pyruvate fermentation to acetaldehyde and ethanol, was recently reported as being up-regulated in acetic acidgrown ISA1307 cells compared to cells grown on glucose [16]. Moreover, the deletion of PDC1, coding for $S$. cerevisiae pyruvate decarboxylase, was found to lead to a susceptibility phenotype in cells exposed to acetic and propionic acids $[7,8]$.

Among the strong candidate determinants of acetic acid tolerance we identified GYP8 and WSC4 homologues, putatively involved in cellular transport, in particular vesicular transport. The processes of transport vesicle formation,

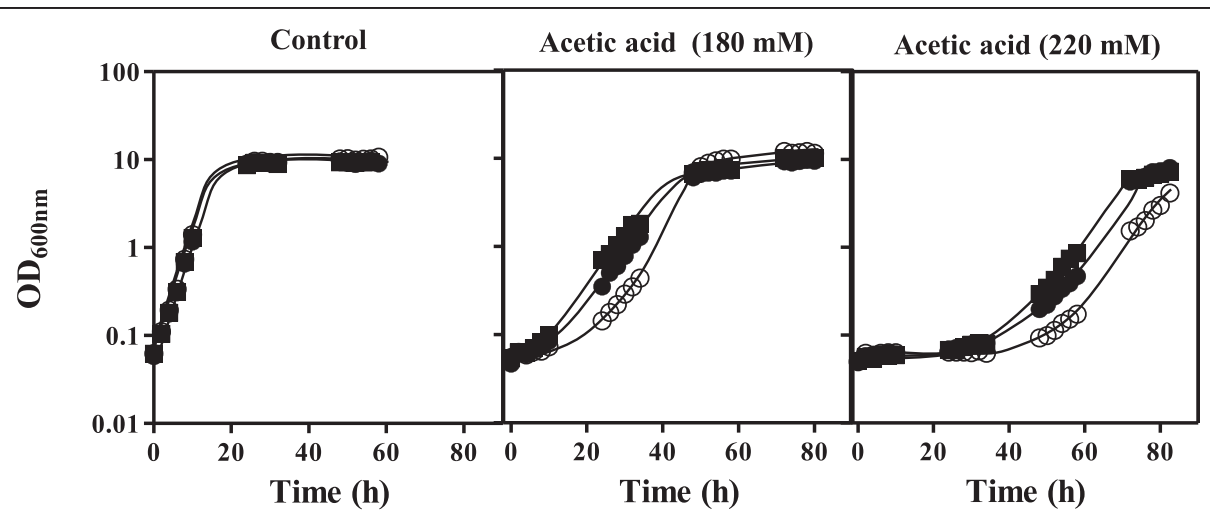

Fig. 6 Effect of the expression of an extra copy of Z. bailii IST302 genes ZbMSN4 or ZbTIF3 in this same strain. Growth curves of Z. bailii IST302

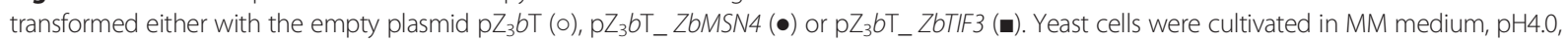
either or not supplemented with acetic acid (180 mM or $220 \mathrm{mM}$ ). The growth curves shown are representative of three independent assays 
targeting, docking and tethering require complex molecular machinery. Different Ras-like GTPases contribute to these activities by acting as key regulators in assembling specific protein complexes at different donor and target membranes [21-23]. In S. cerevisiae, GYP8 encodes a GTPase-activating protein for Ypt/Rab GTPases, which plays an essential function in endoplasmic reticulum to Golgi vesicular protein transport. S. cerevisiae gyp $8 \Delta$ was found to be sensitive to acetic acid and the expression of the Z. bailii GYP8 homologue, sharing 99 \% identity with $Z$. bailii CLIB213 ${ }^{\mathrm{T}}$, led to a suppression of the mutant phenotype providing evidences of a similar function in $Z$. bailii. To our best knowledge, this is the first time that this gene is related with increased tolerance to acetic acid in yeast. Also in the context of cellular transport, we found that the expression of WSC4 homologue (presumably derived from the non- $Z$. bailii parental strain) suppresses the susceptibility phenotype of $S$. cerevisiae wsc4 $\Delta$ mutant. S. cerevisiae Wsc4 is specifically involved in the translocation of soluble secretory proteins and insertion of membrane proteins into the ER membrane. In addition to its role in protein trafficking activity, Wsc4 was also described to play a role in S. cerevisiae response to a number of stresses, namely to heat shock, exposure to ethanol or 4-nitroquinoline 1-oxide (4-NQO), a DNA-damaging agent [24]. To our knowledge, there is no published information about the increased susceptibility to weak acids of wsc $4 \Delta$ mutant, but the WSC4 gene was found to be upregulated after exposure to acetic acid by two-fold in $S$. cerevisiae [6]. Moreover, it is known that this gene is coregulated by the weak acid-responsive transcription factors Haal and Rim101 in response to acetic acid stress [6].

Genes homologous to S. cerevisiae RKR1, PMT1 and KTR7, putatively involved in modification and degradation of proteins, were also considered strong candidate determinants of acetic acid tolerance. In S. cerevisiae, both PMT1 and KTR7 code for mannosyltransferases that have been described as key enzymes for protein glycosylation known to be essential for cell wall rigidity [25, 26]. The remodelling of cell wall is considered a common response to several environmental stresses [8]. In the specific case of weak acid stress, such remodelling is known to be an essential adaptive response that presumably leads to the reduction of the diffusion rate of the undissociated weak acid form into the cell interior, limiting the futile cycle resulting from the continuous uptake of the lipophilic form by passive diffusion followed by the active expulsion of the counterion through specific transporters [27, 28]. Remarkably, the family-related $S$. cerevisiae gene KTR4, encoding another mannosyltransferase involved in protein glycosylation, was previously identified as a determinant of acetic acid tolerance [8].

The ILV3 homologue was also identified as a strong candidate determinant of acetic acid tolerance. In $S$. cerevisiae, ILV3 codes for a dihydroxyacid dehydratase that catalyzes the third step in the pathways leading to biosynthesis of branched-chain amino acids [29]. Interestingly, the content of Ilv3 was found to be higher in acetic acid-challenged yeast cells, compared with unstressed cells [30].

Among the DNA inserts identified during the present work, the best inserts whose expression confers a high protective effect against acetic acid stress in both the parental and the deletion mutant strains are S06 and those containing MSN4 or TIF3 homologues.

The ORF ZBAI_02295, one of two ORFs included in S06 insert and presumably involved in membrane trafficking, was identified as being responsible for the considerable increase in the acetic acid tolerance of the haa $1 \Delta$ mutant, but not of the parental strain, thereby suggesting that the expression of ZBAI_02295 can support the function of Haa1 targets in S. cerevisiae but cannot, at least individually, further enhance the acetic acid tolerance of the parental strain. The contribution of the encoding protein, containing a functional domain associated to the uncharacterised DUP family to acetic acid tolerance, is still unclear. DUP proteins were previously suggested as being connected to membrane trafficking and hypothesized as being involved in the trafficking of membrane transporters $[20,31]$. Results gathered from large-scale chemical genomics screenings suggest that intracellular trafficking processes are required for weak acid tolerance [9]. Moreover, the genes of the DUP240 family in S. cerevisiae YAR028W and $Y A R 029 \mathrm{~W}$ were found to be up-regulated, their transcription being Haal dependent, in cells exposed to acetic acid stress [6], reinforcing the idea that this family of proteins is involved in yeast response and tolerance to acetic acid and that the expression of ZBAI_02295 in haa1D can compensate the abolishment of YAR028W and YAR029W transcription and therefore elevate the acetic acid susceptibility of the mutant up to the level of the parental strain. This increase of tolerance was not observed in the parental cells maybe because the putative membrane protein originated from the ORF ZBAI_02295 does not bring any advantage in cells where the Haal regulon is transcribed. The fact that the expression of S06 insert, which contains ZBAI_02295 and ZBAI_02296, leads to the increase of the acetic acid tolerance of the parental strain may be due to the conjugated effect of both ORFs and also to the different conditions used, namely the medium composition and the cloning vector. The expression of the genes from S06 DNA insert under the control of their native promoters compared with the individual expression of each gene under the GAL1 inducible promoter can be different and it is likely that the overproduction of the two putative membrane proteins encoded by these ORFs might be deleterious to the host cell. 
The relevance of TIF3 homologue as a putative translation initiation factor in yeast tolerance to acetic acid may rely on the fact that stressed cells generate stressresponsive programmes consisting on a specific upregulation of translation initiation towards the induction of specific adaptation proteins, while a rapid inhibition of protein synthesis in general occurs, in order to rationalize the consumption of resources [32]. Using the nonflocculating $Z$. bailii strain IST302, it was possible to confirm that the increased expression of ZbTIF3 in this same strain enhances its tolerance to acetic acid.

ISA1307 MSN4 gene is homologous to S. cerevisiae paralogous genes encoding the transcription factors Msn2 and Msn4. These transcription factors are involved in the regulation of genes of the general stress response and, despite their high homology, both proteins play non-redundant and condition-specific roles in gene expression regulation in S. cerevisiae [33]. Interestingly, it was found that both the Haa1 and Msn2/4 regulons share a total of 23 acetic acidactivated genes [6]. For this reason, it is likely that the strain ISA1307 Msn4 homologue has the ability to suppress haa1D susceptibility phenotype in $S$. cerevisiae. Remarkably, ISA1307 Msn4 homologue was indeed one of the best acetic acid susceptibility suppressors found in the screening. Moreover, the expression of ZbMSN4 from IST302 either in $S$. cerevisiae parental strains BY4741 and W303-1A or the derived deletion mutants msn4A and $m s n 2 \Delta m s n 4 \Delta$ confers increased protection against acetic acid, indicating that ZbMsn4 has a role similar to its homologous $S$. cerevisiae protein. In addition, the increased expression of ZbMSN4 in $Z$. bailii IST302 also elevated this strain's tolerance to acetic acid, confirming this putative transcription factor as an important determinant of acetic acid resistance in Z. bailii.

\section{Conclusions}

In the present study we have identified several strong candidate determinants of tolerance to acetic acid in the intrinsically highly acetic acid tolerant $Z$. bailii-derived hybrid strain ISA1307. Specifically, this is the case of the following $S$. cerevisiae homologues presumably involved in different cellular processes - GYP8 and WSC4 (cellular transport and transport routes), PMT1, KTR7 and RKR1 (protein fate), TIF3 (protein synthesis), ILV3 (amino acid metabolism), MSN4 (transcription) - and of ZBAI_02295 (homologous to membrane proteins of unknown function and presumably involved in cellular trafficking). The overexpression of ZbMSN4 and ZbTIF3 genes, which were confirmed as playing a relevant role in acetic acid tolerance in yeast through their homologous and heterologous expression in $Z$. bailii and $S$. cerevisiae strains, may be useful considering the improvement of yeast cell robustness against acetic acid if the objective is their use as cell factories.

\section{Methods \\ Strains and growth media}

The Saccharomyces cerevisiae deletion mutant strain BY4741_haa1 $\Delta$, derived from the parental strain BY4741 (MATa, his $3 \Delta 1$, leu2 $\Delta 0$, met15 $\Delta 0$, ura $3 \Delta 0$ ) and obtained from the EUROSCARF collection was used as the host strain for the screening of acetic acid determinants of tolerance in a Zygosaccharomyces bailii-derived interspecies hybrid strain ISA1307 using a previously constructed genomic library [15]. Strains gyp $8 \Delta, k \operatorname{tr} 7 \Delta, r k r 1 \Delta, m s n 4 \Delta$, pmt $1 \Delta$, tif $3 \Delta$ and $w s c 4 \Delta$ derived from the same $S$. cerevisiae parental strain were used for phenotype complementation assays. Since the deletion of ILV3 gene in the haploid background strain BY4741 is lethal, the ilv3A mutant used in phenotype complementation assays was derived from the diploid parental strain BY4743 (MATa/a, his $3 \Delta 1 /$ his $3 \Delta 1$, leu $2 \Delta 0 /$ leu $2 \Delta 0$, lys $2 \Delta 0 / L Y S 2$, MET15/ met $15 \Delta 0$, ura $3 \Delta 0 /$ ura $3 \Delta 0$ ) with one copy of ILV3 deleted. S. cerevisiae strains W303-1A (MATa, leu2 $\Delta 3,112 \operatorname{trp} 1 \Delta 1$, can $1 \Delta 100$, ura $3 \Delta 1$, ade $2 \Delta 1$, his $3 \Delta 11,15)$ and derived double deletion mutant msn2 $\Delta m s n 4 \Delta$ [34] were used for complementation assays of MSN4 from Z. bailii IST302 (ZbMSN4). This strain was isolated from a spontaneous fermentation of grape must from Douro wine-producing areas and its genome was recently sequenced and annotated in our laboratory (unpublished results). The taxonomic identification of $Z$. bailii IST302 was confirmed by comparing the partial $26 \mathrm{~S}$ ribosomal DNA sequence (Additional file 3) with other DNA sequences from Z. bailii strains using the Basic Local Alignment Search Tool (BLAST) of the National Center for Biotechnology Information (NCBI). Strain IST302 was used for the amplification of ZbMSN4 and ZbTIF3 genes that were cloned into $\mathrm{pZ}_{3} b \mathrm{~T}$. This strain was also used as a host cell for the expression of an extra copy of its ZbMSN4 and ZbTIF3 genes. Escherichia coli XL1-Blue was used for plasmid maintenance and general cloning procedures. E. coli cells were grown in Luria-Bertani medium (LB), supplemented with $150 \mu \mathrm{g} / \mathrm{ml}$ ampicillin when required. Yeast strains were batch-cultured at $30{ }^{\circ} \mathrm{C}$ with orbital agitation (250 rpm) in liquid mineral medium (MM) that contains, per litre: $1.7 \mathrm{~g}$ yeast nitrogen base without amino acids or $\left(\mathrm{NH}_{4}\right)_{2} \mathrm{SO}_{4}$ (Difco Laboratories, Detroit, Mich.), 20 g glucose (Merck) and $2.65 \mathrm{~g}\left(\mathrm{NH}_{4}\right)_{2} \mathrm{SO}_{4}$ (Merck). Supplementation was needed for auxotrophic strains either with $20 \mathrm{mg}$ methionine, $20 \mathrm{mg}$ histidine, $60 \mathrm{mg}$ leucine and $20 \mathrm{mg}$ uracil for growth of BY4741 and BY4743 background strains (MM4), or with $20 \mathrm{mg}$ histidine, $60 \mathrm{mg}$ leucine, $40 \mathrm{mg}$ tryptophan, $80 \mathrm{mg}$ adenine and $20 \mathrm{mg}$ uracil for growth of W303-1A background strains (MM5) (all from Sigma, Spain). For transformants selection, yeast 
strains were grown in MM4 or MM5 media without uracil supplementation. YPD medium (2 \% glucose (Merck), $1 \%$ yeast extract (Difco) and $2 \%$ peptone (Difco)) was used for yeast cells' maintenance and to grow cells for transformation experiments. Solid media were obtained by adding $20 \mathrm{~g}$ of agar to each litre of the corresponding liquid media. All strains were maintained at $-80{ }^{\circ} \mathrm{C}$ in appropriate media supplemented with $15 \%$ glycerol $(\mathrm{v} / \mathrm{v})$.

\section{Screening of the genomic library from Z. bailii-derived interspecies hybrid strain ISA 1307 \\ Transformation of S. cerevisiae BY4741_haa1A with strain ISA1307 genomic library}

The ISA1307 strain genomic library constructed by Rodrigues et al. [15] in the pRS316 vector [35] was used in this work. This plasmid is a shuttle vector for $S$. cerevisiae and E. coli, containing origins of replication for both species and $A m p^{r}$ and URA3 genes as selection markers. Moreover, this cloning vector is a centromeric plasmid, possessing an $S$. cerevisiae centromere (CEN6). The choice for a low copy plasmid is useful for isolation of genes that may have a toxic effect when present in multiple copies. For library plasmid DNA isolation, E. coli cells containing the genomic library were grown at $26{ }^{\circ} \mathrm{C}$ on $\mathrm{LB}$ medium supplemented with ampicillin until late stationary-phase and plasmid DNA was extracted from these cells using the QIAprep ${ }^{\circ}$ Spin Maxiprep Kit according to the manufacturer's instructions. S. cerevisiae BY4741_haa1s strain was transformed with library plasmid DNA, using the lithium acetate method [36]. The transformation mixture was plated onto solid MM4 medium without uracil and plates were incubated at $30{ }^{\circ} \mathrm{C}$ for 3 days.

\section{Screening of the transformants for acetic acid tolerance}

Selection of the transformants showing more tolerance to acetic acid was performed in 96-well microplates containing liquid MM4 medium without uracil at $\mathrm{pH}$ 4.0. At the end of the day, a first plate containing $200 \mu \mathrm{l}$ of liquid medium was inoculated with cells taken from the different yeast transformants under study, and incubated at $30{ }^{\circ} \mathrm{C}$ overnight with orbital agitation at $250 \mathrm{rpm}$. On the next morning, each inoculum was diluted and used to inoculate a microplate containing the same liquid media supplemented with $60 \mathrm{mM}$ of acetic acid, at an initial $\mathrm{OD}_{600 \mathrm{~nm}}$ of about 0.05 . This plate was incubated at $30{ }^{\circ} \mathrm{C}$ for $24 \mathrm{~h}$ under stirring at $250 \mathrm{rpm}$ and after that time period the culture $\mathrm{OD}_{600 \mathrm{~nm}}$ was measured (VersaMax microplate reader, Molecular Devices). The tolerance of transformants to acetic acid was based on these values of growth observed after $24 \mathrm{~h}$ of incubation. Candidates were considered susceptible to acetic acid when $\mathrm{OD}_{600 \mathrm{~nm}}$ reached values below 0.250 , while candidates with an intermediate tolerance phenotype to acetic acid exhibited an $\mathrm{OD}_{600 \mathrm{~nm}}$ between 0.250 and 0.350 and the tolerant candidates an $\mathrm{OD}_{600 \mathrm{~nm}}$ above 0.350 . S. cerevisiae BY4741_haa1D was used as the negative control as it is particularly susceptible to $60 \mathrm{mM}$ acetic acid, $\mathrm{pH} 4.0$, being unable to grow within the period of incubation used.

\section{Comparison of the tolerance of the selected candidates to acetic acid}

A confirmation screening of acetic acid tolerance phenotype was performed with the isolation of total DNA from yeast transformants selected as the most tolerant to acetic acid. DNA was used to transform $E$. coli XL1-Blue strain competent cells by electroporation using Bio-Rad Gene Pulser II (400 $\Omega, 25 \mu \mathrm{F}$, $2.5 \mathrm{kV})$. The transformants obtained were selected for ampicillin resistance and cultivated for $12 \mathrm{~h}$ in $3 \mathrm{ml}$ of LB liquid medium with ampicillin at $37{ }^{\circ} \mathrm{C}$ with an orbital agitation of $250 \mathrm{rpm}$. For plasmid isolation from E. coli a QIAprep Spin Miniprep Kit was used, according to the manufacturer's instructions. The extracted DNA was then used to transform the parental strain S. cerevisiae BY4741 and the derived deletion mutant BY4741_haa1D, using the lithium acetate method [36]. Growth curves of these strains in liquid media, either in the absence or presence of acetic acid were determined. Cells were grown in MM4 medium without uracil at $\mathrm{pH} 4.0$ until exponential phase $\left(\mathrm{OD}_{600 \mathrm{~nm}}\right.$ of $\left.0.5 \pm 0.05\right)$ and then re-inoculated at an $\mathrm{OD}_{600 \mathrm{~nm}}$ of 0.05 , in $50 \mathrm{ml}$ of fresh medium, either or not supplemented with $60 \mathrm{mM}$ of acetic acid. Growth was followed by measuring culture $\mathrm{OD}_{600 \mathrm{~nm}}$ during batch cultivation at $30{ }^{\circ} \mathrm{C}$ with an orbital agitation of $250 \mathrm{rpm}$. The parental strain S. cerevisiae BY4741 and the mutant BY4741_haa1D both transformed with the empty vector were used as controls. The suppressors of acetic acid susceptibility phenotype of BY4741_haa1s were selected and submitted to further sequence analysis. Finally, an additional confirmation step of the phenotype of BY4741_haa1s cells transformed with the sequenced suppressors was performed by repeating their growth curves in control conditions and in the presence of $60 \mathrm{mM}$ of acetic acid in 96-well microplates (FilterMax F5, Multi-mode microplate reader, Molecular Devices), at $30{ }^{\circ} \mathrm{C}$. Microplate reads were carried out every 10 min using a $595 \mathrm{~nm}$ absorbance filter. An orbital agitation of three seconds was performed prior to each read. The growth curves of $S$. cerevisiae BY4741 parental strain transformed with these same suppressors were repeated as well. The plates were inoculated with cells in exponential phase $\left(\mathrm{OD}_{600 \mathrm{~nm}}\right.$ of $\left.0.5 \pm 0.05\right)$ at an initial $\mathrm{OD}_{600 \mathrm{~nm}}$ of 0.05 . 
In order to be comparable, all the growth curves must come from the same plate, since the level of inhibition of the acid is hardly reproducible from plate to plate due to the extremely small volume contained in each well. So, all the parental strain transformants were grown in the same plate, and the same was done for the transformants of the deletion mutant BY4741_haa1D. For comparison purposes between the transformants from the two different backgrounds, the growth curve of the parental strain with the empty vector was included in the plates with the BY4741_haa1D transformants.

\section{In silico analysis of the selected plasmid DNA inserts from strain ISA1307 genomic library}

The complete DNA sequence of the selected plasmid inserts from strain ISA1307 genomic library was obtained in two steps. First, approximately $1000 \mathrm{bp}$ of the DNA sequence ends of each plasmid insert were sequenced using vector specific primers (forward and reverse). Second, the complete sequence of the plasmid insert was acquired by alignment of the sequenced ends against the genome sequence of the strain ISA1307 available in the PEDANT database (http://pedant.helmholtz-muenchen.de/genomes.jsp?Category=fungal) [37]. This sequence was part of a high-throughput DNA sequencing project, based on Illumina paired-end sequencing, carried out by our group [14]. The in silico analysis of each DNA plasmid insert from the genomic library was performed also using the PEDANT database and the genomic browser GBrowse_syn (http://mips.helmholtzmuenchen.de/gbrowse2/cgi-bin/gbrowse_syn/zbailii) [38] that returns all the putative open reading frames (ORFs) present in the DNA fragment based on sequence homology with S. cerevisiae. Additionally, this tool provides the synteny alignments for the $Z$. bailii-derived interspecies hybrid strain ISA1307 genome versus the genomes of Z. bailii CLIB213 ${ }^{\mathrm{T}}$, Z. rouxii and S. cerevisiae. When the plasmid DNA insert contained truncated ORFs, the presence of specific functional domains was assessed using the Conserved Domain Database of the NCBI [19]. The description of each gene was based on the information gathered in Saccharomyces Genome Database (www.yeastgenome.org) for the corresponding putative homologue.

\section{Cloning and expression of ZBAI_02295 and ZBAI_02296 in S. cerevisiae}

The pGREG506 plasmid from the DRAG \& DROP collection [39] was used to individually clone by homologous recombination and express the genes ZBAI_02295 and ZBAI_02296 identified in the S06 DNA fragment from ISA1307 genomic library. That cloning vector was acquired from Euroscarf and contains a HIS3 gene under the control of a galactose inducible promoter (GAL1) and the yeast selectable marker URA3. During homologous recombination the HIS3 gene is replaced by the gene of interest. ZBAI_02295 and ZBAI_02296 DNA fragments were generated by $\mathrm{PCR}$ using genomic DNA extracted from the strain ISA1307 and the specific primers ZBAI_02295_FWD, ZBAI_02295_REV, ZBAI_02296_FWD and ZBAI_02296_REV, whose sequences are listed in Additional file 4. The cDNA from each gene was co-transformed into the parental strain BY4741 and derived deletion mutant haa1s with the pGREG506 vector, previously cut with SalI restriction enzyme. The recombinant plasmids pGREG506_ZBAI_02295 and pGREG506_ZBAI_02296 were obtained through homologous recombination in yeast. Correct cloning of each ORF was confirmed by DNA sequencing. Additionally, $S$. cerevisiae BY4741 parental and derived deletion mutant haa1s strains were transformed with the cloning vector pGREG506. To have the adequate control cells, both strains were transformed as well with the empty vector pGREG506 with the HIS3 gene deleted (pGREG506_noHIS3, obtained by digestion of pGREG506 with the restriction enzyme Sall), since in the recombinant vector the HIS3 gene is substituted by the insert of interest. The susceptibility to acetic acid of the parental strain BY4741 and the derived deletion mutant haa1 $\triangle$, harbouring each one of the four described plasmids (pGREG506_ ZBAI_02295, pGREG 506_ ZBAI_02296, pGREG506 and pGREG506_noHIS3) was assessed. This was possible by comparing their growth curves in liquid MM4-U medium supplemented with $1 \%$ of galactose $(\mathrm{w} / \mathrm{v}) \mathrm{pH} 4.0$, at $30{ }^{\circ} \mathrm{C}$ with orbital agitation (250 rpm), either or not supplemented with $60 \mathrm{mM}$ acetic acid, as previously described.

\section{Complementation of $S$. cerevisiae deletion mutants by the corresponding Z. bailii ISA1307 single genes present in genomic library plasmids}

The genomic library plasmids 8.23, 18.22, 23.1, B02, B18, S07 and Y08 carrying the single S. cerevisiae putative homologous genes GYP8, PMT1, WSC4, MSN4, TIF3, KTR7 or RKR1, respectively, were transformed in S. cerevisiae BY4741 EUROSCARF mutants lacking the respective gene. The complementation of library plasmid 23.17 carrying ILV3 was performed using the diploid BY4743 parental strain with one copy of the essential ILV3 gene deleted, because the haploid BY4741_ilv3s is unviable. Both S. cerevisiae parental strains transformed with the empty vector were used as control. The transformants were batch-cultivated in MM4-U medium at $\mathrm{pH} 4.0$, either or not supplemented with $60 \mathrm{mM}$ of acetic acid, as previously described. Since $S$. cerevisiae tif $3 \Delta$ is highly susceptible to acetic acid, a growth medium containing a lower concentration of acetic acid $(40 \mathrm{mM})$ was used. The 
complementation assays using the diploid strains derived from BY4743 were performed with a higher concentration $(65 \mathrm{mM})$ of acetic acid.

\section{Cloning and expression of ZbMSN4 in S. cerevisiae}

The gene ZbMSN4 amplified from $Z$. bailii IST302 was cloned by homologous recombination into pGREG506 using the strategy above described for the cloning of ZBAI_02295 and ZBAI_02296. The primers ZbMSN4_pGREG_FWD and ZbMSN4_pGREG_REV (Additional file 4) were used for the amplification of ZbMSN4 coding region. This DNA fragment and the pGREG506 vector previously digested with SalI restriction enzyme were co-transformed into $S$. cerevisiae BY4741 parental strain. The obtained recombinant plasmid pGREG506_ZbMSN4 was digested with SpeI and $A s c \mathrm{I}$ restriction enzymes to remove the GAL1 promoter from the vector. The digested vector and $S$. cerevisiae MSN4 promoter (approximately 1000 bp upstream the start codon) that was amplified with primers ZbMSN4prom_FWD and ZbMSN4prom_REV (Additional file 4) were co-transformed into S. cerevisiae BY4741 parental cells. The recombinant vector pGREG506_ promMSN4Sc_ZbMSN4 obtained by homologous recombination was sequenced to confirm the correct cloning of the promoter region and the gene and transformed afterwards into S. cerevisiae BY4741_msn4A, W303-1A parental and derived double deletion mutant $m s n 2 \Delta m s n 4 \Delta$ strains. The susceptibility to acetic acid of the parental strains BY4741 and W303-1A and of the corresponding derived deletion mutants $m s n 4 \Delta$ and $m s n 2 \Delta m s n 4 \Delta$, harbouring pGREG506_promMSN4Sc_ZbMSN4 and also pGREG506_ noHIS3 was assessed by comparing their growth curves in liquid MM4-U (BY4741 background strains) and MM5-U (W303-1A background strains), either or not supplemented with the appropriate acetic acid concentration.

\section{Cloning and expression of an extra copy of ZbMSN4 and ZbTIF3 in Z. bailii IST302}

The expression of an extra copy of ZbMSN4 and ZbTIF3 genes in the parental strain Z. bailii IST302 was performed by cloning these genes by homologous recombination into the centromeric expression vector $\mathrm{pZ}_{3} b \mathrm{~T}$ [40] linearized with XbaI. The genes ZbMSN4 and ZbTIF3 and their corresponding promoters (approximately $1000 \mathrm{bp}$ upstream the start codon) were amplified from strain IST302 genomic DNA using the primers ZbMSN4_FWD, ZbMSN4_REV, ZbTIF3_FWD and ZbTIF3_REV (Additional file 4) and cotransformed with the linearized $\mathrm{pZ}_{3} b \mathrm{~T}$ into $S$. cerevisiae BY4741. Selection of the transformants holding the recombinant vectors $\mathrm{pZ}_{3} b \mathrm{~T}_{-} Z b M S N 4$ and $\mathrm{pZ}_{3} b \mathrm{~T}_{-}$ ZbTIF3 was performed in YPD plates containing G418 $(200 \mathrm{mg} / \mathrm{L})$. The correct recombination was confirmed by sequencing the obtained plasmids. The recombinant plasmids and the empty plasmid were used to transform Z. bailii IST302 using a commercial yeast transformation kit (MP Biomedicals, California) with minor modifications. The susceptibility to acetic acid of $Z$. bailii IST302 cells transformed with $\mathrm{pZ}_{3} b \mathrm{~T}$ or with the recombinant vectors $\mathrm{pZ}_{3} b \mathrm{~T}_{-} Z b M S N 4$ and $\mathrm{pZ}_{3} b \mathrm{~T}_{-}$ZbTIF3 was assessed by comparing their growth curves in liquid MM either or not supplemented with 180 or $220 \mathrm{mM}$ acetic acid.

\section{Availability of supporting data}

All the supporting data of this article is included within the article and in its additional files. The partial sequence of the 26S ribosomal RNA gene of $Z$. bailii strain IST302 (Additional file 3) is deposited in GeneBank (accession number: KU194200).

\section{Additional files}

Additional file 1: Figure S1. Growth curves of the 31 transformants selected as the best candidates. S. cerevisiae BY4741_haa1D (A) and BY4741 parental (B) strains transformed with the empty vector $(\varnothing)$ and with the 31 selected vectors from ISA1307 genomic library (legend included in the chart). Yeast cells were grown in MM4 medium ( $\mathrm{pH} 4.0$ ) without uracil, supplemented with $60 \mathrm{mM}$ acetic acid. The curves are representative of at least three independent assays. (PPTX $675 \mathrm{~kb}$ )

Additional file 2: Genomic DNA inserts from the strain ISA1307 found to rescue the acetic acid susceptibility phenotype of $S$. cerevisiae BY4741_haa1D. Based on ISA1307 annotated genome, several complete and incomplete ORFs were identified in each fragment. (PDF $182 \mathrm{~kb}$ )

Additional file 3: Partial sequence of the 265 ribosomal RNA gene of $Z$. bailii strain IST302. (PDF $4 \mathrm{~kb}$ )

Additional file 4: List of primers used in this work. All the primers contain a region with homology to the gene/region to be amplified (italics) and a nucleotide sequence with homology to the cloning site flanking region of the vector used for recombination (underlined). (PDF $170 \mathrm{~kb}$ )

\section{Competing interests}

The authors declare that they have no competing interests.

\section{Authors' contributions}

MP and FCR performed the comparative analysis of the tolerance to acetic acid of the selected candidates, the in silico analysis of the selected DNA inserts and the subcloning, complementation and overexpression assays. MP, FCR and JFG constructed all the recombinant plasmids and strains prepared for this study. They all contributed to the writing of the manuscript under the scientific supervision of IS-C who conceived and coordinated the study. JFG, NPM and LQ performed the screening of the genomic library transformants for the identification of genes required for maximal tolerance to acetic acid. All authors read and approved the final manuscript.

\section{Acknowledgements}

We thank Dr. Paola Branduardi (University of Milano-Bicocca) for providing $\mathrm{pZ}_{3} b T$ plasmid and Dr. Marian Carlson (Columbia University) for the double deletion S. cerevisiae mutant $m s n 2 \Delta m s n 4 \Delta$.

Funding received by iBB-Institute for Bioengineering and Biosciences from FCT-Portuguese Foundation for Science and Technology (UID/BIO/04565/ 2013) and from Programa Operacional Regional de Lisboa 2020 (Project N. 007317) is acknowledged. FCT supported post-doctoral grant to MP (SFRH/ BPD/73306/2010) and PhD grants to FCR (SFRH/BD/82226/2011) and JFG (SFRH/BD/80065/2011). LQ was an Erasmus exchange student from Institut Universitaire de Technologie de Dijon, France. 
Received: 22 April 2015 Accepted: 8 December 2015 Published online: 16 December 2015

\section{References}

1. Stratford M. Food and beverage spoilage yeasts. In: Querol A, Fleet G, editors. Yeasts in food and beverages. New York: Springer; 2006. p. 335-79.

2. Sá-Correia I, Guerreiro JF, Loureiro-Dias MC, Leão C, Côrte-Real M. Zygosaccharomyces. In: Batt CA, Tortorello ML, editors. Encyclopedia of Food Microbiology, vol 3. Elsevier Ltd, Academic Press. 2014. pp. 849-55. ISBN: 9780123847300.

3. Piper $\mathrm{P}$, Calderon CO, Hatzixanthis $\mathrm{K}$, Mollapour M. Weak acid adaptation: the stress response that confers yeasts with resistance to organic acid food preservatives. Microbiology. 2001;147:2635-42.

4. Teixeira MC, Mira NP, Sá-Correia I. A genome-wide perspective on the response and tolerance to food-relevant stresses in Saccharomyces cerevisiae. Curr Opin Biotechnol. 2011;22:150-6.

5. Fernandes AR, Mira NP, Vargas RC, Canelhas I, Sá-Correia I. Saccharomyces cerevisiae adaptation to weak acids involves the transcription factor Haa1p and Haa1p-regulated genes. Biochem Biophys Res Commun. 2005;337:95-103.

6. Mira NP, Becker JD, Sá-Correia I. Genomic expression program involving the Haa1p-regulon in Saccharomyces cerevisiae response to acetic acid. OMICS. 2010;14:587-601.

7. Mira NP, Lourenço AB, Fernandes AR, Becker JD, Sá-Correia I. The RIM101 pathway has a role in Saccharomyces cerevisiae adaptive response and resistance to propionic acid and other weak acids. FEMS Yeast Res. 2009;9: 202-16

8. Mira NP, Palma M, Guerreiro JF, Sá-Correia I. Genome-wide identification of Saccharomyces cerevisiae genes required for tolerance to acetic acid. Microb Cell Fact. 2010;9:79. doi:10.1186/1475-2859-9-79.

9. Mira NP, Teixeira MC, Sá-Correia I. Adaptive response and tolerance to weak acids in Saccharomyces cerevisiae: a genome-wide view. OMICS. 2010;14: $525-40$.

10. Holyoak CD, Stratford M, McMullin Z, Cole MB, Crimmins K, Brown AJ, et al. Activity of the plasma membrane $\mathrm{H}^{+}$)-ATPase and optimal glycolytic flux are required for rapid adaptation and growth of Saccharomyces cerevisiae in the presence of the weak-acid preservative sorbic acid. Appl Environ Microbiol. 1996:62:3158-64.

11. Pampulha ME, Loureiro MC. Combined effect of acetic acid, $\mathrm{pH}$ and ethanol on intracellular pH of fermenting yeast. Appl Microbiol Biotechnol. 1989;31: 547-50

12. Carmelo V, Santos H, Sá-Correia I. Effect of extracellular acidification on the activity of plasma membrane ATPase and on the cytosolic and vacuolar pH of Saccharomyces cerevisiae. Biochim Biophys Acta. 1997;1325:63-70.

13. Macpherson N, Shabala L, Rooney H, Jarman MG, Davies JM. Plasma membrane $\mathrm{H}^{+}$and $\mathrm{K}^{+}$transporters are involved in the weak-acid preservative response of disparate food spoilage yeasts. Microbiology. 2005; 151:1995-2003.

14. Mira NP, Münsterkötter M, Dias-Valada F, Santos J, Palma M, Roque FC, et al. The genome sequence of the highly acetic acid-tolerant Zygosaccharomyces bailii-derived interspecies hybrid strain ISA1307, isolated from a sparkling wine plant. DNA Res. 2014;21:299-313.

15. Rodrigues F, Zeeman AM, Alves C, Sousa MJ, Steensma HY, Côrte-Real M, et al. Construction of a genomic library of the food spoilage yeast Zygosaccharomyces bailii and isolation of the beta-isopropylmalate dehydrogenase gene (ZbLEU2). FEMS Yeast Res. 2001;1:67-71.

16. Guerreiro JF, Mira NP, Sá-Correia I. Adaptive response to acetic acid in the highly resistant yeast species Zygosaccharomyces bailii revealed by quantitative proteomics. Proteomics. 2012:12:2303-18.

17. Sousa MJ, Rodrigues F, Côrte-Real M, Leão C. Mechanisms underlying the transport and intracellular metabolism of acetic acid in the presence of glucose in the yeast Zygosaccharomyces bailii. Microbiology. 1998;144:665-70.

18. Galeote V, Bigey F, Devillers H, Neuvéglise C, Dequin S. Genome sequence of the food spoilage yeast Zygosaccharomyces bailii CLIB 213 ${ }^{\top}$. Genome Announc. 2013:1:e00606-13.

19. Marchler-Bauer A, Lu S, Anderson JB, Chitsaz F, Derbyshire MK, DeWeeseScott $C$, et al. CDD: a conserved domain database for the functional annotation of proteins. Nucleic Acids Res. 2011;39:D225-9.

20. Despons L, Wirth B, Louis VL, Potier S, Souciet J-L. An evolutionary scenario for one of the largest yeast gene families. Trends Genet. 2006;22:10-5.
21. Barlowe C, Orci L, Yeung T, Hosobuchi M, Hamamoto S, Salama N, et al. COPII: a membrane coat formed by Sec proteins that drive vesicle budding from the endoplasmic reticulum. Cell. 1994;77:895-907.

22. Guo W, Sacher M, Barrowman J, Ferro-Novick S, Novick P. Protein complexes in transport vesicle targeting. Trends Cell Biol. 2000;10:251-5.

23. Zerial M, McBride H. Rab proteins as membrane organizers. Nat Rev Mol Cell Biol. 2001:2:107-17.

24. Zu T, Verna J, Ballester R. Mutations in WSC genes for putative stress receptors result in sensitivity to multiple stress conditions and impairment of RIm1-dependent gene expression in Saccharomyces cerevisiae. Mol Genet Genomics. 2001:266:142-55.

25. Gentzsch M, Tanner W. The PMT gene family: protein O-glycosylation in Saccharomyces cerevisiae is vital. EMBO J. 1996;15:5752-9.

26. Lussier M, Sdicu AM, Winnett E, Vo DH, Sheraton J, Düsterhöft A, et al. Completion of the Saccharomyces cerevisiae genome sequence allows identification of KTR5, KTR6 and KTR7 and definition of the nine-membered KRE2/MNT1 mannosyltransferase gene family in this organism. Yeast. 1997; 13:267-74.

27. Simões T, Mira NP, Fernandes AR, Sá-Correia I. The SPII gene, encoding a glycosylphosphatidylinositol-anchored cell wall protein, plays a prominent role in the development of yeast resistance to lipophilic weak-acid food preservatives. Appl Environ Microbiol. 2006:72:7168-75.

28. Mollapour M, Shepherd A, Piper PW. Presence of the Fps1p aquaglyceroporin channel is essential for Hog1p activation, but suppresses Slt2(Mpk1)p activation, with acetic acid stress of yeast. Microbiology. 2009; 155:3304-11.

29. Velasco JA, Cansado J, Peña MC, Kawakami T, Laborda J, Notario V. Cloning of the dihydroxyacid dehydratase-encoding gene (ILV3) from Saccharomyces cerevisiae. Gene. 1993;137:179-85.

30. Almeida B, Ohlmeier S, Almeida AJ, Madeo F, Leão C, Rodrigues F, et al. Yeast protein expression profile during acetic acid-induced apoptosis indicates causal involvement of the TOR pathway. Proteomics. 2009;9:720-32.

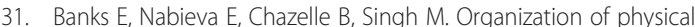
interactomes as uncovered by network schemas. PLoS Comput Biol. 2008;4: e1000203.

32. Simpson CE, Ashe MP. Adaptation to stress in yeast: to translate or not? Biochem Soc Trans. 2012:40:794-9.

33. Berry DB, Gasch AP. Stress-activated genomic expression changes serve a preparative role for impending stress in yeast. Mol Biol Cell. 2008:19:4580-7.

34. Estruch F, Carlson M. Two homologous zinc finger genes identified by multicopy suppression in a SNF1 protein kinase mutant of Saccharomyces cerevisiae. Mol Cell Biol. 1993:13:3872-81.

35. Sikorski RS, Hieter P. A system of shuttle vectors and yeast host strains designed for efficient manipulation of DNA in Saccharomyces cerevisiae. Genetics. 1989;122:19-27.

36. Gietz D, St Jean A, Woods RA, Schiestl RH. Improved method for high efficiency transformation of intact yeast cells. Nucleic Acids Res. 1992;20:1425.

37. Walter MC, Rattei T, Arnold R, Guldener U, Munsterkotter M, Nenova K, et al. PEDANT covers all complete RefSeq genomes. Nucleic Acids Res. 2009;37: D408-11.

38. McKay SJ, Vergara IA, Stajich JE. Using the Generic Synteny Browser (GBrowse syn). Curr Protoc Bioinformatics. 2010;9:12. doi:10.1002/ 0471250953.bi0912s31.

39. Jansen G, Wu C, Schade B, Thomas DY, Whiteway M. Drag\&Drop cloning in yeast. Gene. 2005:344:43-51.

40. Branduardi P, Valli M, Brambilla L, Sauer M, Alberghina L, Porro D. The yeast Zygosaccharomyces bailii: a new host for heterologous protein production, secretion and for metabolic engineering applications. FEMS Yeast Res. 2004; 4:493-504.

41. Simões T, Teixeira MC, Fernandes AR, Sá-Correia I. Adaptation of Saccharomyces cerevisiae to the herbicide 2,4-dichlorophenoxyacetic acid, mediated by Msn2p- and Msn4p-regulated genes: important role of SPI1. Appl Environ Microbiol. 2003;69:4019-28.

42. Kawahata M, Masaki $K$, Fujii T, lefuji $H$. Yeast genes involved in response to lactic acid and acetic acid: acidic conditions caused by the organic acids in Saccharomyces cerevisiae cultures induce expression of intracellular metal metabolism genes regulated by Aft1p. FEMS Yeast Res. 2006;6:924-36. 